\title{
Metabolic fingerprinting, antioxidant characterization, and enzyme-inhibitory response of Monotheca buxifolia (Falc.) A. DC. extracts
}

Joham Sarfraz Ali ${ }^{1}$, Hammad Saleem ${ }^{2,3^{*}}$, Abdul Mannan ${ }^{4}$, Gokhan Zengin ${ }^{5}$, Mohamad Fawzi Mahomoodally ${ }^{6}$, Marcello Locatelli, Syafiq Asnawi Zainal Abidin ${ }^{8}$, Nafees Ahemad ${ }^{2}$ and Muhammad Zia ${ }^{1 *}$

\begin{abstract}
Background: Ethnobotanical and plant-based products allow for the isolation of active constituents against a number of maladies. Monotheca buxifolia is used by local communities due to its digestive and laxative properties, as well as its ability to cure liver, kidney, and urinary diseases. There is a need to explore the biological activities and chemical constituents of this medicinal plant.

Methods: In this work, the biochemical potential of M. buxifolia (Falc.) A. DC was explored and linked with its biological activities. Methanol and chloroform extracts from leaves and stems were investigated for total phenolic and flavonoid contents. Ultrahigh-performance liquid chromatography coupled with mass spectrometry (UHPLCMS) was used to determine secondary-metabolite composition, while high-performance liquid chromatography coupled with photodiode array detection (HPLC-PDA) was used for polyphenolic quantification. In addition, we carried out in vitro assays to determine antioxidant potential and the enzyme-inhibitory response of $M$. buxifolia extracts.
\end{abstract}

\footnotetext{
* Correspondence: hammad.saleem@gmail.com; ziachaudhary@gmail.com

${ }^{2}$ School of Pharmacy, Monash University, Jalan Lagoon Selatan, 47500 Bandar Sunway, Selangor Darul Ehsan, Malaysia

'Department of Biotechnology, Quaid-i-Azam University Islamabad, Islamabad 45320, Pakistan

Full list of author information is available at the end of the article
}

(C) The Author(s). 2020 Open Access This article is licensed under a Creative Commons Attribution 4.0 International License, which permits use, sharing, adaptation, distribution and reproduction in any medium or format, as long as you give appropriate credit to the original author(s) and the source, provide a link to the Creative Commons licence, and indicate if changes were made. The images or other third party material in this article are included in the article's Creative Commons licence, unless indicated otherwise in a credit line to the material. If material is not included in the article's Creative Commons licence and your intended use is not permitted by statutory regulation or exceeds the permitted use, you will need to obtain permission directly from the copyright holder. To view a copy of this licence, visit http://creativecommons.org/licenses/by/4.0/. The Creative Commons Public Domain Dedication waiver (http://creativecommons.org/publicdomain/zero/1.0/) applies to the data made available in this article, unless otherwise stated in a credit line to the data. 
(Continued from previous page)

Results: Phenolics (91 mg gallic-acid equivalent (GAE)/g) and flavonoids (48.86 mg quercetin equivalent (QE)/g) exhibited their highest concentration in the methanol extract of stems and the chloroform extract of leaves, respectively. UHPLC-MS analysis identified a number of important phytochemicals, belonging to the flavonoid, phenolic, alkaloid, and terpenoid classes of secondary metabolites. The methanol extract of leaves contained a diosgenin derivative and polygalacin D, while kaempferol and robinin were most abundant in the chloroform extract. The methanol extract of stems contained a greater peak area for diosgenin and kaempferol, whereas this was true for lucidumol A and 3-O-cis-coumaroyl maslinic acid in the chloroform extract. Rutin, epicatechin, and catechin were the main phenolics identified by HPLC-PDA analysis. The methanol extract of stems exhibited significant 2,2-diphenyl-1-picrylhydrazyl (DPPH) and 2,2'-azino-bis(3-ethylbenzothiazoline-6-sulfonic acid (ABTS) radical-scavenging activities (145.18 and $279.04 \mathrm{mmol}$ Trolox equivalent (TE)/g, respectively). The maximum cupric reducing antioxidant capacity (CUPRAC) (361.4 mg TE/g), ferric-reducing antioxidant power (FRAP) (247.19 mg TE/g), and total antioxidant potential $(2.75 \mathrm{mmol} \mathrm{TE} / \mathrm{g}$ ) were depicted by the methanol extract of stems. The methanol extract of leaves exhibited stronger inhibition against acetylcholinesterase (AChE) and glucosidase, while the chloroform extract of stems was most active against butyrylcholinesterase (BChE) (4.27 mg galantamine equivalent (GALAE)/g). Similarly, the highest tyrosinase (140 mg kojic-acid equivalent (KAE)/g) and amylase $(0.67 \mathrm{mmol}$ acarbose equivalent (ACAE)/g) inhibition was observed for the methanol extract of stems.

Conclusions: UHPLC-MS analysis and HPLC-PDA quantification identified a number of bioactive secondary metabolites of $M$. buxifolia, which may be responsible for its antioxidant potential and enzyme-inhibitory response. M. buxifolia can be further explored for the isolation of its active components to be used as a drug.

\section{Background}

Ethnobotanical plants are considered the provenance of medicines possessing therapeutic potency to cure ailments and fight pathogenic maladies. Distant sanctioned systems of medicine, such as Ayurvedic, Chinese, and Unani medicine, utilize medicinal plants having remedial properties. The concomitant amelioration in technology and science has amplified the global use of medicinal plants due to their pharmacological and nutraceutical potential, highlighting their antioxidant, antimicrobial, anticancer, and enzymeinhibitory properties [1]. Plants and/or plant-based products allow for the isolation of active components against a number of maladies [2]. Such compounds also function as preeminent agents, playing a key role in neutralizing or scavenging free radicals and decomposing peroxides, amongst others. The standardization of plant-based remedies assures the quality and international acceptability of miraculous agents, and much effort is demanded in this respect [3].

Pakistan has diverse genetic resources and a rich floristic wealth of medicinal plants due to favorable climatic conditions. Secondary metabolites are profiled using different techniques, which are then linked with biological activities, before further isolation of the active ingredients in an effort to cure diseases. Monotheca buxifolia belongs to the family Sapotaceae that comprises 800 species and 65 genera. Gurguri is the local name of its fresh fruit that is sold in markets due to its ethnobotanical significance [4]. M. buxifolia is found in barren hilly areas [5]. In Pakistan, it is widely present in Balochistan (i.e., Zhob, Gorakh Hills, and Loralai) and Khyber Pakhtunkhwa (Kohat, Drosh, Chitral, and Attock Districts).
Its distribution is also observed in tribal areas along the border of Afghanistan, i.e., Mohmand Agency and Darraadamkhel [4]. The plant is used as folk medicine in South Asia (Pakistan, India, and Afghanistan) and the Middle East, Iran, and Iraq. According to folk knowledge, $M$. buxifolia has digestive and laxative properties, and the leaves are used to treat liver, kidney, and urinary diseases [6]. The fruit extract has hepatoprotective, ureaseinhibitory, and antibacterial activities [7-9], and it is also known for its pain-, inflammation-, and pyrexiaameliorating properties, mainly due to its oleanolic-acid and isoquercetin contents [10]. A previous study showed that the M. buxifolia fruit has a high amount of phenolics and flavonoids, and it depicts free-radical-scavenging activity [11]. The leaves of $M$. buxifolia are chemically enriched with flavonoids, terpenoids, saponins, anthraquinones, cardiac glycosides, tannins, and reducing sugars depicting high antioxidant activity [12]. The fruit also possesses significant antibacterial and cytotoxic properties, and it is enriched with lupeol and $\alpha$-amyrin [13].

Keeping in view the medicinal value of this plant, the present study was designed to evaluate the phytochemical composition (phenolic and flavonoid contents via ultrahighperformance liquid chromatography coupled with mass spectrometry (UHPLC-MS) analysis, and high-performance liquid chromatography coupled with photodiode array detection (HPLC-PDA)) and biological potential (including the antioxidant-2,2-diphenyl-1-picrylhydrazyl (DPPH), 2,2' azino-bis(3-ethylbenzothiazoline-6-sulfonic acid (ABTS), ferric-reducing antioxidant power (FRAP), cupric reducing antioxidant capacity (CUPRAC), phosphomolybdenum, and 
metal chelation-and enzyme-inhibitory-acetylcholinesterase (AChE), butyrylcholinesterase (BChE), amylase, glucosidase, and tyrosinase-properties) of $M$. buxifolia leaf and stem extracts. In addition, principal component analysis (PCA) statistical studies were carried out to explain the association of bioactive contents with biological activities. These results will provide guidelines for isolating the active constituents from this plant to be employed in pharmaceutical studies.

\section{Methods}

\section{Collection and extraction of plant material}

Fresh plant material (leaves and stems) of Monotheca buxifolia was collected in June 2016 from the Mohmand Agency Mountain, Khyber Pakhtunkhwa, Pakistan (Fig. 1). The plant was identified by Dr. Rizwana Aleem Qureshi (Taxonomist Department of Plant Sciences, Quaid-eAzam University, Islamabad, Pakistan), and a herbarium sample was deposited (voucher ID BIT-4220, Herbarium Quaid-i-Azam University, Islamabad, Pakistan). The plant material was washed, dried under shade, and powdered using an electric grinder. The powdered material (leaves and stems) was separately macerated with analytical-grade methanol (1:3) and subjected to sonication for $30 \mathrm{~min}$ in an ultrasonic bath at room temperature [14]. The marc was filtered through a muslin cloth, followed by filtration through Whatmann filter paper No. 1. The residue was again dipped in methanol, and this procedure was repeated thrice. The filtrates were combined and concentrated using a rotary evaporator (Rotovapor R 200 Buchi, Flawil Switzerland) at $40^{\circ} \mathrm{C}$. The residue was macerated in chloroform (1:3), and the same procedure was followed as stated above to obtain the chloroform extract. The extracts were stored at $4{ }^{\circ} \mathrm{C}$ until further use.

\section{Determination of Total phenolic and flavonoid contents}

The total phenolic and flavonoid contents were evaluated in the extracts following a previously reported protocol [15]. Total phenolic constituents are reported as gallic-acid equivalent (mg GAE/g extract), while total flavonoid contents are reported as quercetin equivalent (mg QE/g extract).

\section{Phytochemical composition of extracts}

The secondary-metabolite profiling of methanol and chloroform extracts of $M$. buxifolia leaves and stems was assessed by utilizing standard reverse-phase (RP)UHPLC-MS analysis as described previously [16]. Similarly, 22 polyphenolic components (gallic acid, catechin, chlorogenic acid, $p-\mathrm{OH}$ benzoic acid, vanillic acid,

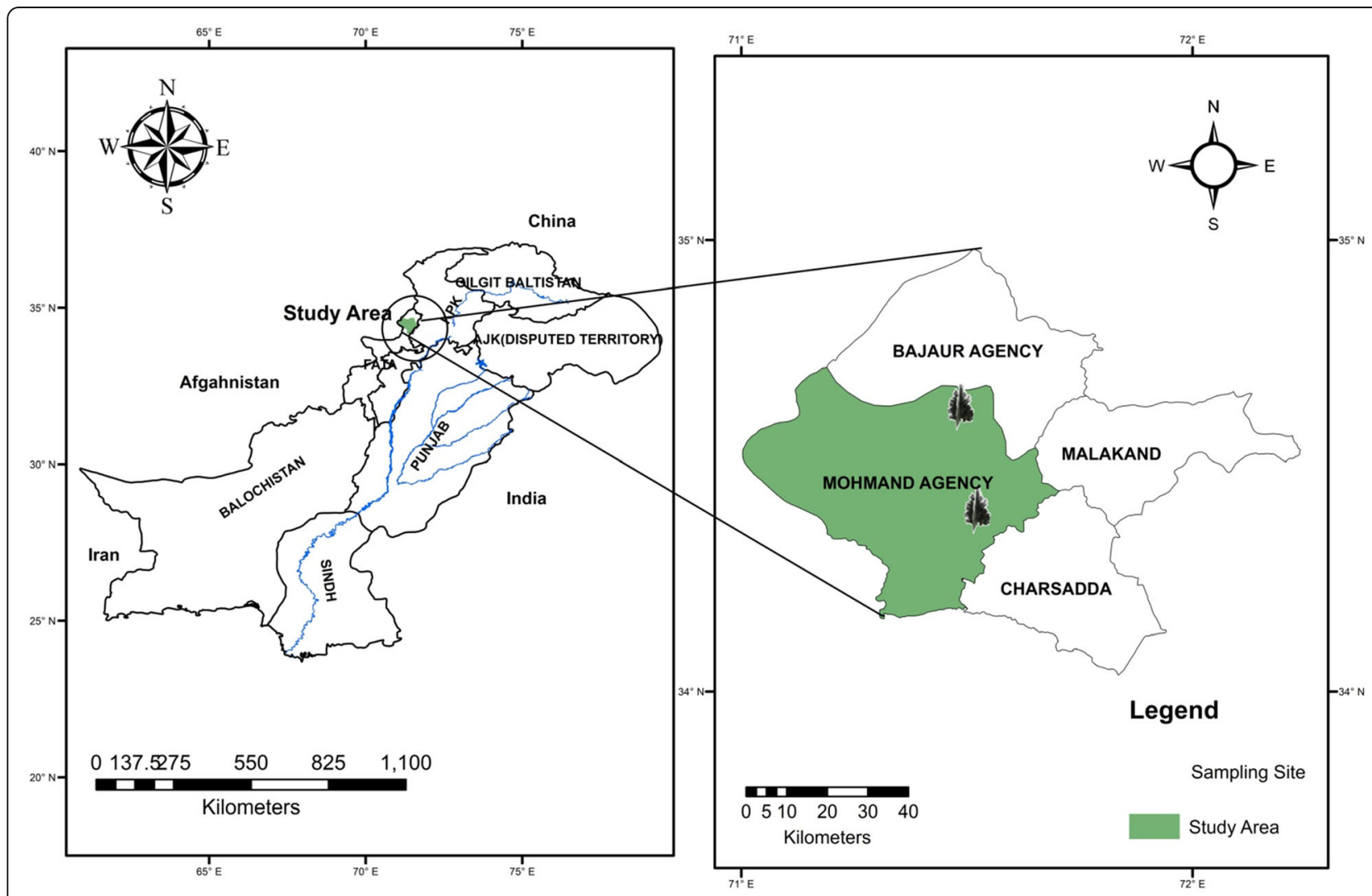

Fig. 1 Map of Pakistan showing Monotheca buxifolia plant collection site Mohmand Agency 
epicatechin, syringic acid, 3-OH benzoic acid, 3-OH-4$\mathrm{MeO}$ benzaldehyde, $p$-coumaric acid, rutin, sinapinic acid, $t$-ferullic acid, naringin, 2.3-diMeO benzoic acid, benzoic acid, $o$-coumaric acid, quercetin, harpagoside, $t$-cinnamic acid, naringenin, and carvacrol; standards purchased from Sigma Aldrich Milan, Italy) were also determined in extracts using HPLC-PDA analysis following a previously reported protocol [15].

\section{Antioxidant assays}

Previously reported standard in vitro methods [17] were followed to estimate the antioxidant properties of all the extracts, including their free-radical-scavenging property (DPPH and ABTS), reducing power potential (FRAP and CUPRAC), phosphomolybdenum-based total antioxidant capacity, and metal-chelating ability. The outcomes are presented as Trolox equivalents in all assays except for the metal-chelating assay where ethylenediaminetetraacetic acid (EDTA) was used as a standard.

\section{Enzyme-inhibitory assays}

The enzyme-inhibitory capacity of all the concentrates against acetylcholinesterase (AChE), butyrylcholinesterase $(\mathrm{BChE})$, tyrosinase, $\alpha$-amylase, and $\alpha$-glucosidase was explored following previously reported standard in vitro bioassays [17]. Galantamine was used as a reference for $\mathrm{AChE}$ and $\mathrm{BChE}$, and the cholinesterase-inhibitory potential was estimated as $\mathrm{mg}$ galantamine equivalent (GALA E)/g extract. The $\alpha$-amylase- and $\alpha$-glucosidase-inhibitory potentials are presented as mmol acarbose equivalent (ACAE)/g extract, while the tyrosinase-inhibitory potential was recorded as mg kojic-acid equivalent (KAE)/g extract.

\section{Statistical analysis}

All assays were carried out in triplicate. The results are expressed as mean values \pm standard deviation (SD). The activities of extracts were differentiated through one-way analysis of variance (ANOVA), followed by Tukey's honestly significant difference post hoc test with $\alpha=0.05$. The analysis was carried out using SPSS v. 14.0. Principal component analysis (PCA) using XLSTAT was applied to the resultant variables from the phytochemical analysis and biological assays.

\section{Results}

\section{Phytochemical composition of extracts}

Determination of the free-radical-scavenging activity, total reducing power, and total antioxidant capacity, and phytochemical (total phenolics and flavonoids) analyses of methanol and chloroform extracts of leaves and stems of Monotheca buxifolia were performed. Phytochemical analysis was also extended using UHPLC-MS and HPLC-PDA for untargeted and targeted metabolites. Clinically important enzyme-inhibitory assays were also performed. Table 1 shows that the methanol and chloroform extracts of $M$. buxifolia leaves and stems contained a significant amount of phenolics and flavonoids. The amount of total phenolic content was higher in the methanol extract of leaves (69.84 $\mathrm{mg}$ GAE/g extract) and stems ( $91.00 \mathrm{mg} \mathrm{GAE} / \mathrm{g}$ extract) as compared to the chloroform extract. The leaves had a significant amount of flavonoids in both methanol $(40.11 \mathrm{mg} \mathrm{RE} / \mathrm{g})$ and chloroform (48.86 mg RE/g) extracts.

The secondary-metabolite components of M. buxifolia leaf and stem extracts were determined using liquid chromatography coupled with mass spectrometry. A typical chromatogram of the extracts with massspectrometric detection in negative ion mode exhibited complex patterns of peaks (Fig. 2a-d). UHPLC-MS analysis of the methanol extract of leaves revealed the presence of 16 compounds (Table 2), the majority of which were flavonoids, phenolics, and terpenoid derivatives. The most abundant components identified were a diosgenin derivative (an alkaloid) and polygalacin D (an organooxygen). Flavonoids such as kaempferol derivatives and robinin acquired major peaks in the UHPLCMS analysis of the chloroform extract of leaves. UHPLC-MS analysis of the methanol extract of stems revealed the presence of 10 different compounds (Table 3). The alkaloid diosgenin had the greatest peak area (1353.63), followed by the flavonoid kaempferol. Moreover, the chloroform extract of stems depicted the presence of eight compounds (Table 3), including lucidumol A, 3-O-cis-coumaroyl maslinic acid (a terpenoid derivative), and mangostenone $B$ (a benzopyran), as the major components. The results also suggested the occurrence of other important metabolites, the majority of which belonged to diverse classes including flavonoids, phenolics, terpenoids, alkaloids, and fatty-acid derivatives. HPLC-PDA analysis was carried out to gain insight into the polyphenolic profile of $M$. buxifolia leaf and stem extracts (Table 4). The results show that the methanol extract of leaves and the chloroform extract of stems contained the most phenolic compounds. Epicatechin was detected in all samples with maximum quantification $(1.29 \mu \mathrm{g} / \mathrm{mg})$ in the methanol extract of stems. Rutin and catechin were also present in all samples except for the chloroform extract of stems and leaves. However, catechin was quantified in a higher amount in the methanol extract of stems as compared to the other extracts. Similarly, rutin was quantified in a significantly higher amount in the chloroform extract of leaves as compared to the other extracts.

\section{Antioxidant evaluation}

Several different assays were performed including radicalscavenging (DPPH and ABTS), reducing power (CUPRAC and FRAP), ferrous-ion chelation, and phosphomolybdenum 


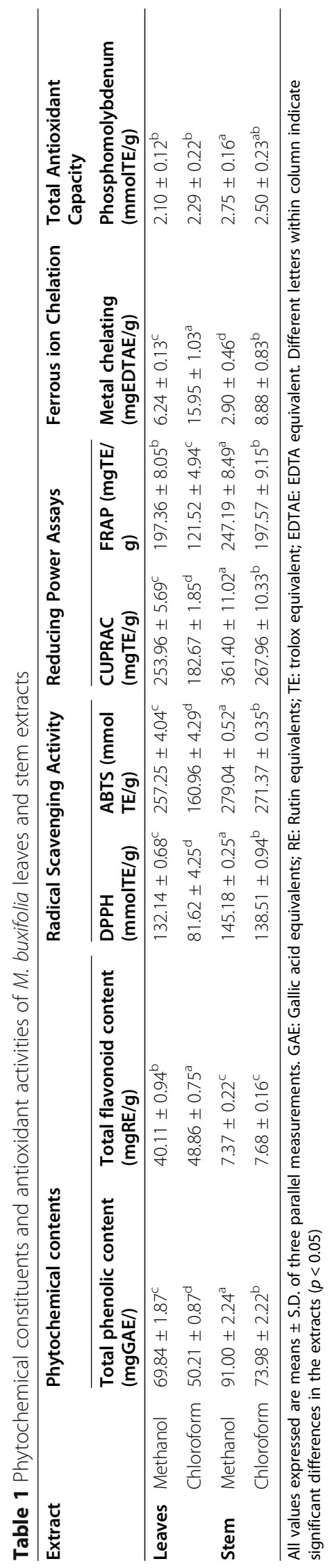




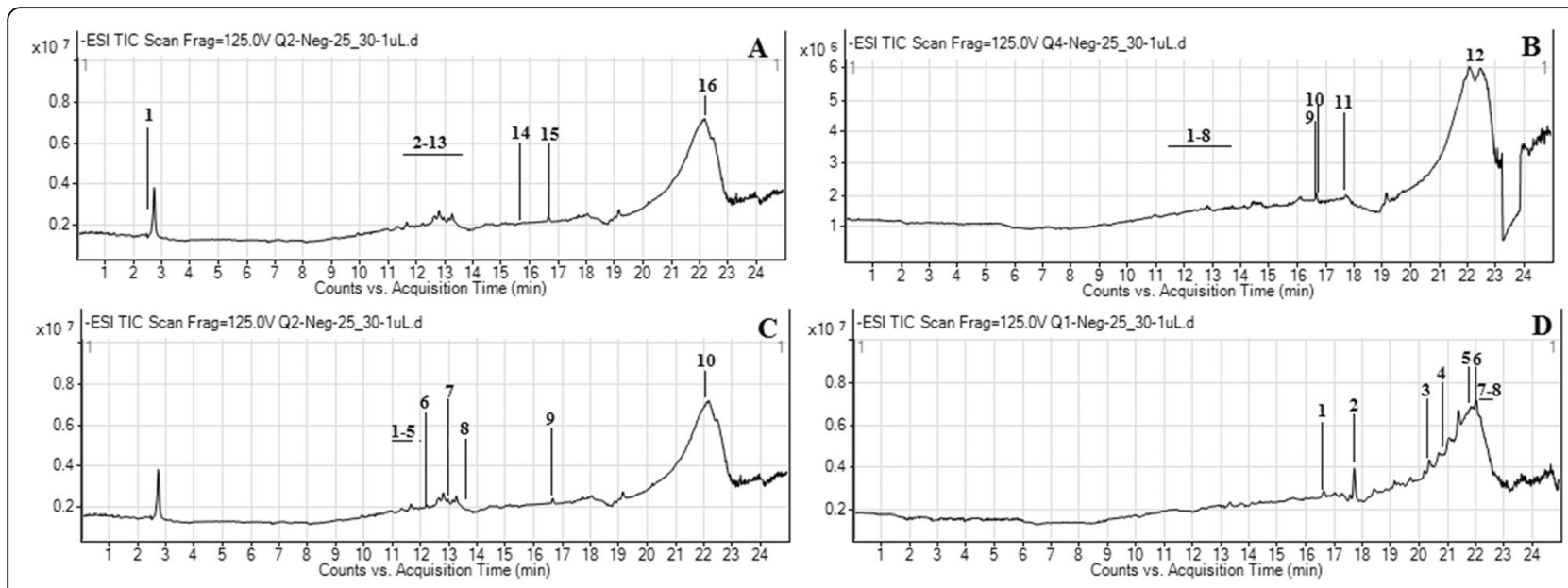

Fig. 2 UHPLC-MS total ion chromatograms (TICS) of M. buxifolia leaves methanol extract (a); M. buxifolia leaves chloroform extract (b); M. buxifolia stem methanol extract (c); (M. buxifolia stem chloroform extract (d)

assays (Table 1). The methanol extract of stems showed prominent free-radical-scavenging activity and reducing power. The DPPH and ABTS assays presented values of $145.18 \mathrm{mmol} \mathrm{TE} / \mathrm{g}$ and $279.04 \mathrm{mmol} \mathrm{TE} / \mathrm{g}$, respectively, for the methanol extract of stems (Table 1). The chloroform extract of leaves showed significant (15.95 mg EDTA equivalent (EDTAE)/g) ferrous-ion-chelating activity. All four extracts showed a nonsignificant difference for the phosphomolybdenum-based total antioxidant response.

\section{Enzyme-inhibitory assays}

The enzyme-inhibitory capabilities of $M$. buxifolia extracts were assessed for five clinically important enzymes, which showed their significant potential (Table 5). The methanol extracts of both parts of the plant and the chloroform extract of stems were most active against $\mathrm{AChE}(4.70,4.66$, and $4.62 \mathrm{mg} \mathrm{GALAE} / \mathrm{g}$, respectively), while, for BChE, the chloroform extract of stems was most potent $(4.27 \mathrm{mg}$ GALAE/g). The stem extracts showed significant tyrosinase- (140.16 and $137.93 \mathrm{mg} \mathrm{KAE/g} \mathrm{inhibition} \mathrm{by} \mathrm{methanol}$ and chloroform extracts, respectively) and amylaseinhibitory activities; however, all four extracts presented equal inhibition of glucosidase activity.

\section{PCA statistical evaluation}

To assess the similarity of the biological activities expressed by the extracts and to analyze the correlations between variables, a principal component analysis (PCA) was performed. The Pearson correlation, as depicted in Fig. 3a, suggests a firm positive correlation between total phenolic content $(r=0.99-0.71)$ and antioxidant potential (except for metal chelation). However, the negative relationship between total phenolic content $(r=-0.94)$ and metal chelation may be due to the antagonistic or synergetic effect of phytochemicals or the presence of some nonphenolic chelators. Similarly, a strong positive relationship ( $r=0.95-0.8)$ was recorded between phenolic content and enzyme-inhibitory activity. In contrast, in the case of flavonoid content, a strong negative correlation was noted with both antioxidant potential $(r=-$ 0.8 to -0.79$)$ and enzyme-inhibitory activity $(r=-0.99$ to -0.54$)$, except for metal-chelation activity, with which flavonoid content was positively correlated $(r=0.66)$. Overall, it was observed that the tyrosinase-inhibitory, FRAP, DPPH, and ABTS activities were the most contributory biological activities to the formation of the first principal component with $p$-values of 0.007, 0.018, 0.019 , and 0.025 , respectively. The bioactive compounds and the biological activity showed an $82.5 \%$ eigenvalue (Fig. 3b), in accordance with the strong correlation between the various activities and the extract components determined through HPLC-PDA.

\section{Discussion}

In recent years, the biological activities (such as anticancer, antimicrobial, antioxidant, and anti-inflammatory) of phenolic compounds and their flavonoid subclass have captured significant attention due to their unique structural and functional properties [18]. Therefore, the determination of total phenolics and flavonoids in plant extracts is advantageous when linking their content with biological activities, which can be further exploited for medicinal use and an immuneboosting response. Table 1 shows that the methanol and chloroform extracts of Monotheca buxifolia leaves and stems contained a significant amount of phenolics and flavonoids. The total phenolic content was higher in the methanol extract as compared to the chloroform extract. Methanol dissolves the polar constituents of plants, including phenolics $[19,20]$; therefore, it is considered the best solvent for the extraction of phenolic compounds. In the case of flavonoid content, the leaf extracts contained a higher amount of flavonoids as compared to the stem extracts. 
Table 2 UHPLC-MS of M. buxifolia leave extracts (negative ionization mode)

\begin{tabular}{|c|c|c|c|c|c|c|}
\hline S/ & $\begin{array}{l}\text { RT } \\
(\min )\end{array}$ & $\begin{array}{l}\text { B. Peak } \\
(\mathrm{m} / \mathrm{z})\end{array}$ & Compound name & Comp. class & $\begin{array}{l}\text { Mol. } \\
\text { formula }\end{array}$ & $\begin{array}{l}\text { Mol. } \\
\text { Mass }\end{array}$ \\
\hline \multicolumn{7}{|c|}{ M. buxifolia Leaves Methanol extract } \\
\hline 1 & 2.574 & 225.06 & Glucoheptonic acid & Sugar Acid & $\begin{array}{l}\mathrm{C}_{7} \mathrm{H}_{14} \\
\mathrm{O}_{8}\end{array}$ & 226.06 \\
\hline 2 & 11.558 & 739.20 & Robinin & Flavonoid & $\begin{array}{l}\mathrm{C}_{33} \mathrm{H}_{40} \\
\mathrm{O}_{19}\end{array}$ & 740.21 \\
\hline 3 & 11.559 & 771.19 & Kaempferol 3-glucoside-7-sophoroside & Flavonoid & $\begin{array}{l}\mathrm{C}_{33} \mathrm{H}_{40} \\
\mathrm{O}_{21}\end{array}$ & 772.20 \\
\hline 4 & 11.761 & 479.08 & $3,5,7,2^{\prime}, 3^{\prime}, 4^{\prime}$-Hexa hydroxy flavone 3-glucoside & Flavonoid & $\begin{array}{l}\mathrm{C}_{21} \mathrm{H}_{20} \\
\mathrm{O}_{13}\end{array}$ & 480.09 \\
\hline 5 & 11.85 & 755.20 & Kaempferol 3-(2G-glucosylrutinoside) & Flavonoid & $\begin{array}{l}\mathrm{C}_{33} \mathrm{H}_{40} \\
\mathrm{O}_{20}\end{array}$ & 756.21 \\
\hline 6 & 11.889 & 609.14 & Robinetin 3-rutinoside & Phenolic & $\begin{array}{l}\mathrm{C}_{27} \mathrm{H}_{30} \\
\mathrm{O}_{16}\end{array}$ & 610.15 \\
\hline 7 & 12.109 & 449.07 & Myricetin 3-alpha-L-arabinopyranoside & Flavonoid & $\begin{array}{l}\mathrm{C}_{20} \mathrm{H}_{18} \\
\mathrm{O}_{12}\end{array}$ & 450.08 \\
\hline 8 & 12.214 & 463.08 & 8-Hydroxyluteolin 8-glucoside & Flavonoid & $\begin{array}{l}\mathrm{C}_{21} \mathrm{H}_{20} \\
\mathrm{O}_{12}\end{array}$ & 464.096 \\
\hline 9 & 12.582 & 433.07 & Avicularin & Flavonoid & $\begin{array}{l}\mathrm{C}_{20} \mathrm{H}_{18} \\
\mathrm{O}_{11}\end{array}$ & 434.08 \\
\hline 10 & 12.962 & 1353.63 & $\begin{array}{l}\text { Diosgenin 3-[glucosyl-(1-> 4)-[glucopyranosyl-(1- > 6)]-glucopyranosyl-(1-> 4)- } \\
\text { rhamnosyl-(1-> 4)-[rhamnosyl-(1-> 2)]-glucoside] }\end{array}$ & Alkaloid & $\begin{array}{l}\mathrm{C}_{63} \mathrm{H}_{102} \\
\mathrm{O}_{31}\end{array}$ & 1354.63 \\
\hline 11 & 13.057 & 171.06 & cis-4-octenedioic acid & Fatty Acid & $\begin{array}{l}\mathrm{C}_{8} \mathrm{H}_{12} \\
\mathrm{O}_{4}\end{array}$ & 172.07 \\
\hline 12 & 13.359 & 1207.57 & Polygalacin D & Organooxygens & $\begin{array}{l}\mathrm{C}_{57} \mathrm{H}_{92} \\
\mathrm{O}_{27}\end{array}$ & 1208.58 \\
\hline 13 & 13.699 & 269.10 & Idebenone Metabolite (Benzenebutanoic acid, 2,5-dihydroxy-3,4-dimethoxy-6-methyl-) & Phenolic & $\begin{array}{l}\mathrm{C}_{13} \mathrm{H}_{18} \\
\mathrm{O}_{6}\end{array}$ & 270.11 \\
\hline 14 & 15.734 & 225.15 & Dihydrojasmonic Acid, Methyl Ester & Phenolic & $\begin{array}{l}\mathrm{C}_{13} \mathrm{H}_{22} \\
\mathrm{O}_{3}\end{array}$ & 226.15 \\
\hline 15 & 16.667 & 221.11 & (6S)-dehydrovomifoliol & Terpenoid & $\begin{array}{l}\mathrm{C}_{13} \mathrm{H}_{18} \\
\mathrm{O}_{3}\end{array}$ & 222.12 \\
\hline 16 & 22.201 & 471.34 & Lucidumol A & Triterpenoid & $\begin{array}{l}\mathrm{C}_{30} \mathrm{H}_{48} \\
\mathrm{O}_{4}\end{array}$ & 472.35 \\
\hline \multicolumn{7}{|c|}{ M. buxifolia Leaves Chloroform extract } \\
\hline 1 & 11.558 & 739.20 & Robinin & Flavonoid & $\begin{array}{l}\mathrm{C}_{33} \mathrm{H}_{40} \\
\mathrm{O}_{19}\end{array}$ & 740.21 \\
\hline 2 & 11.559 & 771.19 & Kaempferol 3-glucoside-7-sophoroside & Flavonoid & $\begin{array}{l}\mathrm{C}_{33} \mathrm{H}_{40} \\
\mathrm{O}_{21}\end{array}$ & 772.20 \\
\hline 3 & 11.61 & 449.10 & 8-C-Glucopyranosyleriodictylol & Flavonoid & $\begin{array}{l}\mathrm{C}_{21} \mathrm{H}_{22} \\
\mathrm{O}_{11}\end{array}$ & 243.05 \\
\hline 4 & 11.85 & 755.20 & Kaempferol 3-(2G-glucosylrutinoside) & Flavonoid & $\begin{array}{l}\mathrm{C}_{33} \mathrm{H}_{40} \\
\mathrm{O}_{20}\end{array}$ & 756.21 \\
\hline 5 & 12.109 & 449.07 & Myricetin 3-alpha-L-arabinopyranoside & Flavonoid & $\begin{array}{l}\mathrm{C}_{20} \mathrm{H}_{18} \\
\mathrm{O}_{12}\end{array}$ & 450.08 \\
\hline 6 & 12.216 & 463.08 & 8-Hydroxyluteolin 8-glucoside & Flavonoid & $\begin{array}{l}\mathrm{C}_{21} \mathrm{H}_{20} \\
\mathrm{O}_{12}\end{array}$ & 567.16 \\
\hline 7 & 13.695 & 269.10 & Idebenone Metabolite (Benzenebutanoic acid, 2,5-dihydroxy-3,4 dimethoxy-6-methyl-) & Phenolic & $\begin{array}{l}\mathrm{C}_{13} \mathrm{H}_{18} \\
\mathrm{O}_{6}\end{array}$ & 270.11 \\
\hline 8 & 15.73 & 225.14 & Dihydrojasmonic Acid, Methyl Ester & Phenolics & $\begin{array}{l}\mathrm{C}_{13} \mathrm{H}_{22} \\
\mathrm{O}_{3}\end{array}$ & 226.15 \\
\hline 9 & 16.664 & 267.12 & Kamahine C & Ketals & $\begin{array}{l}\mathrm{C}_{14} \mathrm{H}_{20} \\
\mathrm{O}_{5}\end{array}$ & 268.13 \\
\hline
\end{tabular}


Table 2 UHPLC-MS of M. buxifolia leave extracts (negative ionization mode) (Continued)

\begin{tabular}{|c|c|c|c|c|c|c|}
\hline $\begin{array}{l}\text { S/ } \\
\text { No }\end{array}$ & $\begin{array}{l}\text { RT } \\
(\min )\end{array}$ & $\begin{array}{l}\text { B. Peak } \\
(\mathrm{m} / \mathrm{z})\end{array}$ & Compound name & Comp. class & $\begin{array}{l}\text { Mol. } \\
\text { formula }\end{array}$ & $\begin{array}{l}\text { Mol. } \\
\text { Mass }\end{array}$ \\
\hline 10 & 16.666 & 221.11 & (6S)-dehydrovomifoliol & Terpenoid & $\begin{array}{l}\mathrm{C}_{13} \mathrm{H}_{18} \\
\mathrm{O}_{3}\end{array}$ & 222.12 \\
\hline 11 & 17.713 & 356.17 & Uplandicine & Alkaloid & $\begin{array}{l}\mathrm{C}_{17} \mathrm{H}_{27} \\
\mathrm{NO}_{7}\end{array}$ & 357.17 \\
\hline 12 & 22.205 & 471.34 & Lucidumol A & Triterpenoid & $\begin{array}{l}\mathrm{C}_{30} \mathrm{H}_{48} \\
\mathrm{O}_{4}\end{array}$ & 472.35 \\
\hline
\end{tabular}

$R T$ retention time, $B$. peak base peak

Table 3 UHPLC-MS of M. buxifolia stem extracts (negative ionization mode)

\begin{tabular}{|c|c|c|c|c|c|c|}
\hline $\begin{array}{l}\text { S/ } \\
\text { No }\end{array}$ & $\begin{array}{l}\text { RT } \\
(\min )\end{array}$ & $\begin{array}{l}\text { B.Peak } \\
(\mathrm{m} / \mathrm{z})\end{array}$ & Compound name & Comp. class & $\begin{array}{l}\text { Mol. } \\
\text { formula }\end{array}$ & $\begin{array}{l}\text { Mol. } \\
\text { Mass }\end{array}$ \\
\hline \multicolumn{7}{|c|}{ M. buxifolia stem methanol extract } \\
\hline 1 & 11.128 & 391.12 & Shanzhiside & $\begin{array}{l}\text { Iridoid } \\
\text { glycoside }\end{array}$ & $\begin{array}{l}\mathrm{C}_{16} \mathrm{H}_{24} \\
\mathrm{O}_{11}\end{array}$ & 527.09 \\
\hline 2 & 11.317 & 577.13 & Apigenin 7-(2"-E-p-coumaroylglucoside) & Flavonoid & $\begin{array}{l}\mathrm{C}_{30} \mathrm{H}_{26} \\
\mathrm{O}_{12}\end{array}$ & 145.07 \\
\hline 3 & 11.341 & 755.20 & Kaempferol 3-(2G-glucosylrutinoside) & Flavonoid & $\begin{array}{l}\mathrm{C}_{33} \mathrm{H}_{40} \\
\mathrm{O}_{20}\end{array}$ & 641.13 \\
\hline 4 & 11.61 & 449.10 & 8-C-Glucopyranosyleriodictylol & Flavonoid & $\begin{array}{l}\mathrm{C}_{21} \mathrm{H}_{22} \\
\mathrm{O}_{11}\end{array}$ & 243.05 \\
\hline 5 & 11.672 & 581.22 & (7'R)-(+)-Lyoniresinol 9'-glucoside & $\begin{array}{l}\text { Lignan } \\
\text { Glycoside }\end{array}$ & $\begin{array}{l}\mathrm{C}_{28} \mathrm{H}_{38} \\
\mathrm{O}_{13}\end{array}$ & 244.90 \\
\hline 6 & 12.216 & 463.08 & 8-Hydroxyluteolin 8-glucoside & Flavonoid & $\begin{array}{l}\mathrm{C}_{21} \mathrm{H}_{20} \\
\mathrm{O}_{12}\end{array}$ & 567.16 \\
\hline 7 & 12.952 & 1353.63 & $\begin{array}{l}\text { Diosgenin 3-[glucosyl-(1-> 4)-[glucopyranosyl-(1-> 6)]-glucopyranosyl-(1- > 4)- } \\
\text { rhamnosyl-(1-> 4)-[rhamnosyl-(1-> 2)]-glucoside] }\end{array}$ & Alkaloid & $\begin{array}{l}\mathrm{C}_{63} \mathrm{H}_{102} \\
\mathrm{O} 31\end{array}$ & 1354.63 \\
\hline 8 & 13.695 & 269.10 & Idebenone Metabolite (Benzenebutanoic acid, 2,5-dihydroxy-3,4-dimethoxy-6-methyl-) & Phenolic & $\begin{array}{l}\mathrm{C}_{13} \mathrm{H}_{18} \\
\mathrm{O}_{6}\end{array}$ & 392.13 \\
\hline 9 & 16.669 & 221.11 & (6S)-dehydrovomifoliol & Terpenoid & $\begin{array}{l}\mathrm{C}_{13} \mathrm{H}_{18} \\
\mathrm{O}_{3}\end{array}$ & 159.98 \\
\hline 10 & 21.036 & 471.34 & Lucidumol A & Triterpenoid & $\begin{array}{l}\mathrm{C}_{30} \mathrm{H}_{48} \\
\mathrm{O}_{4}\end{array}$ & 353.07 \\
\hline \multicolumn{7}{|c|}{ M. buxifolia stem chloroform extract } \\
\hline 1 & 16.63 & 221.11 & (6S)-dehydrovomifoliol & Terpenoid & $\begin{array}{l}\mathrm{C}_{29} \mathrm{H}_{42} \\
\mathrm{O}_{5}\end{array}$ & 222.12 \\
\hline 2 & 17.714 & 356.17 & Uplandicine & Alkaloid & $\begin{array}{l}\mathrm{C}_{30} \mathrm{H}_{48} \\
\mathrm{O}_{5}\end{array}$ & 357.17 \\
\hline 3 & 20.376 & 257.15 & Cicutoxin & Fatty Alcohol & $\begin{array}{l}\mathrm{C}_{29} \mathrm{H}_{46} \\
\mathrm{O}_{4}\end{array}$ & 258.16 \\
\hline 4 & 20.816 & 461.19 & Mangostenone B & Benzopyran & $\begin{array}{l}\mathrm{C}_{20} \mathrm{H}_{24} \\
\mathrm{O}_{2}\end{array}$ & 462.20 \\
\hline 5 & 21.814 & 297.24 & cis-9,10-Epoxystearic acid & Lineolic Acid & $\begin{array}{l}\mathrm{C}_{16} \mathrm{H}_{32} \\
\mathrm{~N}_{6} \mathrm{O}_{5}\end{array}$ & 298.25 \\
\hline 6 & 22.066 & 339.23 & Plastoquinone 3 & $\begin{array}{l}\text { Isoprenoid } \\
\text { quinone }\end{array}$ & $\begin{array}{l}\mathrm{C}_{23} \mathrm{H}_{32} \\
\mathrm{O}_{2}\end{array}$ & 340.24 \\
\hline 7 & 22.164 & 471.34 & Lucidumol A & Triterpenoid & $\begin{array}{l}\mathrm{C}_{30} \mathrm{H}_{48} \\
\mathrm{O}_{4}\end{array}$ & 472.35 \\
\hline 8 & 22.2 & 617.38 & 3-O-cis-Coumaroyl maslinic acid & Triterpenoid & $\begin{array}{l}\mathrm{C}_{39} \mathrm{H}_{54} \\
\mathrm{O}_{6}\end{array}$ & 618.39 \\
\hline
\end{tabular}


Table 4 HPLC-PDA polyphenolic quantification of the tested $M$. buxifolia leaves and stem extracts $(\mu \mathrm{g} / \mathrm{mg})$

\begin{tabular}{|c|c|c|c|c|}
\hline \multirow{2}{*}{$\begin{array}{l}\text { Polyphenoilic } \\
\text { compounds }\end{array}$} & \multicolumn{2}{|l|}{ Leaves } & \multicolumn{2}{|l|}{ Stem } \\
\hline & Methanol & Chloroform & Methanol & Chloroform \\
\hline Gallic acid & nd & $\mathrm{Nd}$ & nd & BLQ \\
\hline Catechin & $4.29 \pm 0.52$ & $\mathrm{Nd}$ & $7.75 \pm 0.84$ & $3.95 \pm 0.86$ \\
\hline Vanillic acid & nd & BLQ & nd & nd \\
\hline Epicatechin & $0.59 \pm 0.05$ & $0.89 \pm 0.08$ & $1.29 \pm 0.95$ & $0.82 \pm 0.08$ \\
\hline 3-OH benzoic acid & nd & $\mathrm{Nd}$ & nd & $0.79 \pm 0.09$ \\
\hline Rutin & $0.74 \pm 0.08$ & $13.7 \pm 1.54$ & $0.45 \pm 0.04$ & nd \\
\hline Naringin & $0.27 \pm 0.03$ & $\mathrm{Nd}$ & nd & nd \\
\hline
\end{tabular}

Values are means SD of three measurements; BLD: below limit of detection < $0.1 \mu \mathrm{g} / \mathrm{mL}$; BLQ: below limit of quantification $<0.2 \mu \mathrm{g} / \mathrm{mL}$; nd: not detected Chlorogenic acid, $\mathrm{p}-\mathrm{OH}$ benzoic acid, Syringic acid, 3-OH-4-MeO benzaldehyde, p-coumaric acid, Sinapinic acid, t-ferullic acid, 2.3-diMeO benzoic acid, Benzoic acid, o-coumaric acid, Quercetin, Harpagoside, t-cinnamic acid, Naringenin, and Carvacrol were not detected in any of the tested extracts

UHPLC-MS analysis of the methanol extract of leaves revealed the presence of flavonoids, phenolics, and terpenoid derivatives, with the most abundant compounds being a diosgenin derivative and polygalacin $\mathrm{D}$, whereas kaempferol and robinin were abundantly present in the chloroform extract of leaves. The UHPLC-MS analysis of the stem extract revealed the presence of diverse components including alkaloids, flavonoids, terpenoids, and benzopyran derivatives as the major components. The presence of diverse phytochemicals is in agreement with a previous study that reported a number of secondary metabolites from this plant [12]. Chromatographic fingerprinting, including HPLC- and mass-spectrumbased identification of compounds, is a powerful tool for the separation and recognition of phytoconstituents [21]. A number of food and medicinal plants have been processed for primary- and secondary-metabolite determination [22] to establish a possible link between their phytocomponents and beneficial bioactivities. It is well known that the polyphenolics and flavonoids, as well as their glycosides, are responsible for antioxidant, anticancer, and cardioprotective activity [23]. The HPLC-PDA analysis results showed that the leaf and stem extracts contained diverse phenolic compounds, with epicatechin, rutin, and catechin as the most abundant. Plants contain different classes of phenols, including polyphenols, flavonoids, phenolic acids, stilbenes, and lignins, which are involved in the protection against and cure of diseases such as cancers, cardiovascular diseases, diabetes, and others [23, 24]. Flavonoids are the most abundant polyphenol in human diets. Dietary polyphenols may activate endogenous defense systems and regulate cellular-signaling processes $[25,26]$. Phenolic contents are also recognized to reduce the risk of chronic diseases, increase healthy lifespan, and promote active healthy aging [27]. For example, epicatechin and catechin have diverse biological properties, including antioxidant, antimicrobial, anti-inflammatory, antitumor, and cardioprotective activity [28, 29]. Rutin was also observed in a significant amount in the leaves and stems of M. buxifolia. Rutin has antioxidant properties, which enable protection from cellular damage caused by free radicals. It also helps to eliminate cholesterol from the body and maintain healthy collagen, and it has anti-inflammatory and anticarcinogenic properties, amongst others [30].

Antioxidants are agents that scavenge free radicals, preventing cellular damage [31]. Reductants are involved in donating hydrogen atoms and breaking down freeradical chains [32]. Phenols and reductants are good electron donors [33]. An inadequate supply of free radicals may damage DNA, protein, and lipid molecules, and it may disrupt membrane phospholipids, thereby leading to diseases and cancer [34]. The methanol extract of stems showed prominent DPPH and ABTS free-radical scavenging activity and reducing power. However, the chloroform extract significantly quenched ferrous ions, showing noteworthy chelating activity. Oxidative stress is related to many health issues such as malignancy, diabetes, cardiac and neurodegenerative disorders, amongst others. Synthetic antioxidants can be used to cure the diseases; however, they may damage vital organs. Therefore, natural antioxidants are of prime importance for better health [35]. The antioxidative response of $M$. buxifolia, such as its free-radical-scavenging activity, reducing power, and metal-chelating ability, was found to be linked to the presence of antioxidants $[4,14]$. Furthermore, it was reported that the solvent used, the plant part used, the mode of processing, and the fractionation scheme influence the extraction of antioxidants and their activities. A number of phytochemicals, such as $3-\mathrm{OH}$

Table 5 Enzyme inhibition assays of M. buxifolia leaves and stem extracts

\begin{tabular}{|c|c|c|c|c|c|c|}
\hline \multicolumn{2}{|l|}{ Extract } & \multirow{2}{*}{$\frac{\text { AChE (mgGALAE/g) }}{4.70 \pm 0.08^{\mathrm{a}}}$} & \multirow{2}{*}{$\frac{\text { BChE (mgGALAE/g) }}{3.01 \pm 0.60^{b}}$} & \multirow{2}{*}{$\frac{\text { Tyrosinase }(\mathbf{m g K A E} / \mathbf{g})}{132.90 \pm 1.68^{\mathrm{b}}}$} & \multirow{2}{*}{$\begin{array}{l}\text { Amylase (mmolACAE/g) } \\
0.56 \pm 0.06^{\mathrm{b}}\end{array}$} & \multirow{2}{*}{$\begin{array}{l}\text { Glucosidase (mmolACAE/g) } \\
59.50 \pm 0.25^{a}\end{array}$} \\
\hline Leaves & Methanol & & & & & \\
\hline & Chloroform & $3.87 \pm 0.07^{b}$ & $2.05 \pm 0.20^{c}$ & $121.31 \pm 0.38^{c}$ & $0.56 \pm 0.02^{b}$ & $58.28 \pm 0.37^{\mathrm{a}}$ \\
\hline \multirow[t]{2}{*}{ Stem } & Methanol & $4.66 \pm 0.04^{a}$ & $3.95 \pm 0.42^{\mathrm{ab}}$ & $140.16 \pm 2.27^{a}$ & $0.67 \pm 0.03^{\mathrm{a}}$ & $59.48 \pm 0.10^{\mathrm{a}}$ \\
\hline & Chloroform & $4.62 \pm 0.03^{\mathrm{a}}$ & $4.27 \pm 0.55^{\mathrm{a}}$ & $137.93 \pm 0.87^{\mathrm{a}}$ & $0.66 \pm 0.05^{a}$ & $59.09 \pm 0.09^{a}$ \\
\hline
\end{tabular}

All values expressed are means \pm S.D. of three parallel measurements. GALAE: galatamine equivalent; KAE: kojic acid equivalent; ACAE: acarbose equivalent. Different letters within column indicate significant differences in the extracts $(p<0.05)$ 


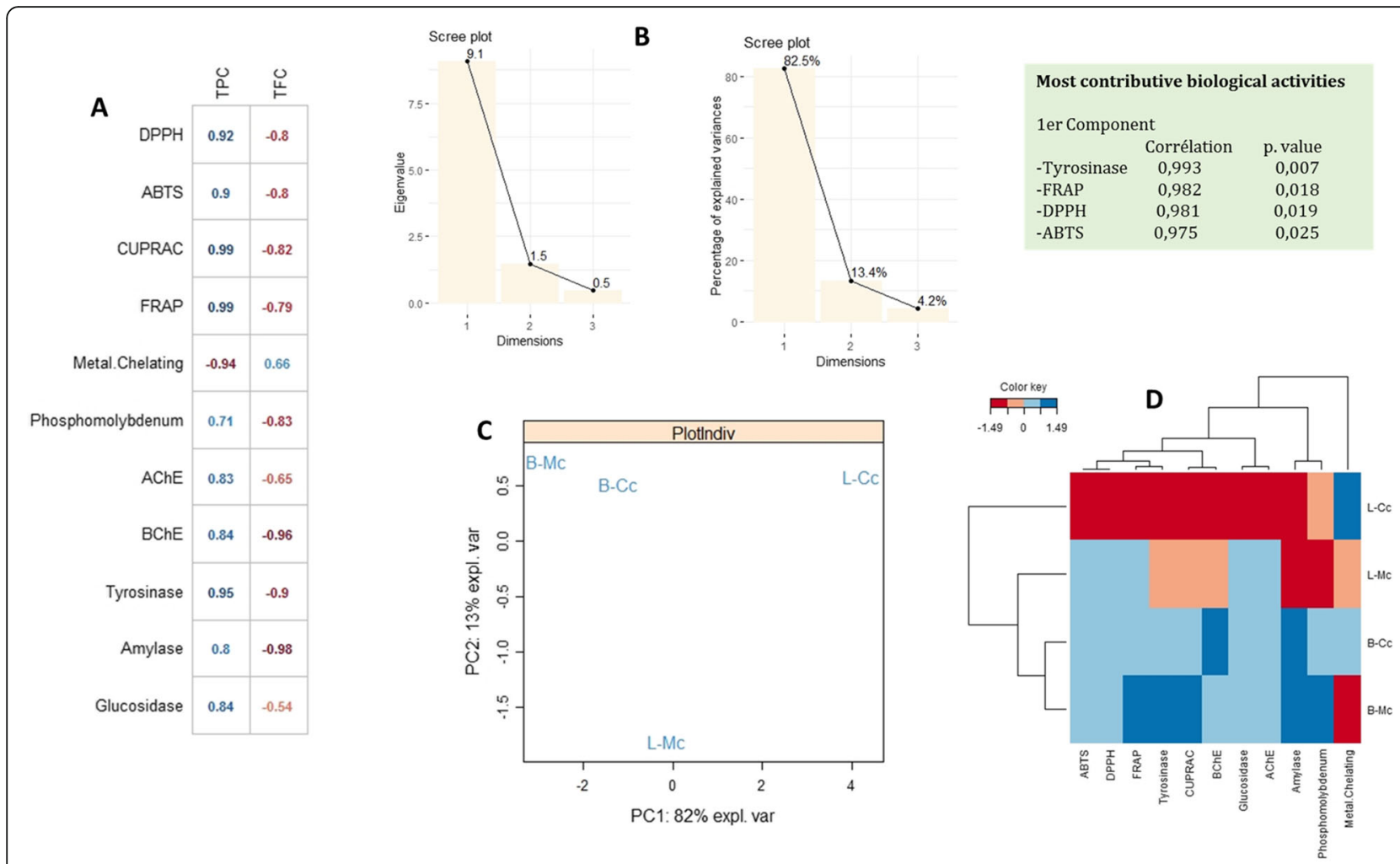

Fig. 3 Statistical evaluations, a: Correlation coefficients between phyto constituents and biological activities ((r), $p<0.05)$; $\mathbf{b}$ : Eigen values and percentage of variability expressed by the factors; $\mathbf{c}$ : Projection of samples into the subspace PC1vsPC2; $\mathbf{d}$ : Heat map of extracts in according to bioactive compounds and biological activities

benzoic acid and epicatechin, were reported to have antioxidative potential [36]. Chelation agents that bind to pro-oxidant metals are regarded as active secondary antioxidants $[37,38]$. These results are also in agreement with studies showing that the antioxidant activity is proportional to the phenolic compound content, which is associated with the solvent used $[39,40]$. The extracts in this study also presented antioxidant activity via the ironchelation and radical-scavenging assays, thereby indicating the presence of both primary and secondary antioxidants. Primary antioxidants neutralize free radicals to prevent the initiation and propagation of oxidative chain reactions, while secondary antioxidants suppress radical formation and protect against oxidative damage [41].

Enzyme-inhibitory assays are a potent tool to assess the significant health benefits of medicinal plants, dietary supplements, and nutraceuticals [42]. Due to the drastic prevalence of several ailments, there is an urgency to address these health hazards, which commonly include Alzheimer's disease and diabetes. M. buxifolia extracts showed prominent inhibitory activity against clinically important enzymes. The methanol extracts of both parts of the plant and the chloroform extract of stems were most active against AChE, while the chloroform extract of stems was the most potent against BChE.
Acetylcholinesterase (AChE) is localized at the cholinergic synapses and regulates neurotransmission through rapid hydrolysis of the neurotransmitter acetylcholine into choline and acetate [43, 44]. Inhibition of AChE can increase the levels of acetylcholine, thereby providing symptomatic relief [45]. On the other hand, butyrylcholinesterase $(\mathrm{BChE})$ is a serine hydrolase associates with lipid metabolism and indicators of metabolic syndrome such as body mass index, waist-hip ratio, waist circumference, weight, cholesterol, and triglyceride levels [46-48]. Increased $\mathrm{BChE}$ activity may also lead to a greater degradation of acetylcholine, which lowers the inhibitory effect on the production of cytokines [49]. Furthermore, amylase and glucosidase play a vital role in the digestion of carbohydrates. In diabetes and obesity, inhibition of these enzymes is essential to reduce carbohydrate digestion [50]. The stem extracts showed significant tyrosinase- and amylase-inhibitory activity; however, all fours extracts depicted equal activity inhibition of glucosidase activity. The significant enzyme-inhibitory potential of $M$. buxifolia extracts is therapeutically important, which suggests its potential use as promising antidiabetic medicine. Inhibition of $\alpha$-amylase is an efficacious approach to overcoming postprandial hyperglycemia $[51,52]$. Tyrosinase is one of the key enzymes responsible for the biosynthesis of 
melanin, and its inhibition is considered the best strategy to treat epidermal hyperpigmentation problems [53]. Tyrosinase also causes browning of fruits and vegetables, leading to quicker degradation and deterioration of nutritional value [54]. The use of tyrosinase inhibitors has attracted great attention in the cosmetic and pharmaceutical industries due to their preventive effects in pigmentation disorders. This scenario demands deliberate action involving the use of enzyme-inhibitory compounds as an effective strategy [54].

PCA analysis suggested a firm positive correlation between total phenolic content and antioxidant activity. This positive association of phenolics with antioxidant activity is in accordance with previous studies showing such a trend [42]. However, the negative relationship in a few cases may be due to the antagonistic or synergetic effect of phytochemicals or the presence of some nonphenolic chelators [17]. A strong correlation was also identified between enzyme-inhibitory potential and phytochemical content through biological assays and HPLC analysis. The bioactive compounds and the biological activity showed a considerable eigenvalue, in accordance with the strong correlation between the various activities and the extract components determined through HPLC-PDA.

\section{Conclusion}

This study concludes that Monotheca buxifolia contains a diverse range of phytochemicals with significant biological activities. The stem extract contained a high amount of phenolics, while flavonoids were most prominent in the leaf extract. The free-radical-scavenging activity, reducing power, and antioxidative potential show that the plant can be used as a nutraceutical to heal stress in the body. Furthermore, the significant enzymeinhibitory activity, especially against AChE, BChE, and tyrosinase, shows that the plant is clinically important as a potential cure for diseases. The prominent amylaseand glycosidase-inhibitory activity of the extracts is in accordance with folk knowledge linking this plant with digestive and laxative properties. The UHPLC-MS analysis and HPLC-PDA quantification identified a number of bioactive secondary metabolites, including phenolics, flavonoids, alkaloids, and terpenoid derivatives, which may be responsible for the plant's significant antioxidant and enzyme-inhibitory potential. The observed activities of this plant could act as a starting point in the identification and isolation of bioactive compounds with antioxidant and enzyme-inhibitory potential.

\section{Abbreviations}

ABTS: 2,2'-Azino-bis(3-ethylbenzothiazoline-6-sulfonic acid) diammonium salt; ACAE: acarbose equivalent; AChE: acetylcholinesterase;

BChE: butyrylcholinesterase; CUPRAC: CUPric Reducing Antioxidant Capacity; DPPH: 2,2-diphenyl-1-picrylhydrazyl; EDTAE: EDTA equivalent; FRAP: Ferricreducing antioxidant power; GAE: gallic acid equivalent; GALAE: galantamine equivalents; HPLC-PDA: high performance liquid chromatography equipped with photodiode array detector; KAE: kojic acid equivalent; PCA: Principal Component Analysis; QE: quercetin equivalent; RE: rutin equivalents; TE: Trolox equivalent; UHPLC-MS: Ultrahigh performance liquid chromatography-mass spectrometer

\section{Acknowledgments \\ Not Applicable.}

\section{Authors' contributions}

JSA and AM conceived the idea, collected plant material, prepared the extracts, and wrote the manuscript. HS, SAZA and NA performed UHPLC-MS of extracts and interpreted the data. GZ performed enzyme inhibition assays, MFM worked on phytochemical analysis and biological activities. ML performed HPLC-PDA analysis. MZ proof read the manuscript and supervised the project. The authors read and approved the final manuscript.

\section{Funding}

The research work was funded by Higher Education Commission, Pakistan. Project No. NRPU-4220.

\section{Availability of data and materials}

All the data of this study is included in the manuscript.

Ethics approval and consent to participate

Not Applicable.

\section{Consent for publication}

All authors are agreed for publication in BMC Complementary Medicine and Therapies.

\section{Competing interests}

Authors declare no conflict of interest.

\section{Author details}

${ }^{1}$ Department of Biotechnology, Quaid-i-Azam University Islamabad, Islamabad 45320, Pakistan. ${ }^{2}$ School of Pharmacy, Monash University, Jalan Lagoon Selatan, 47500 Bandar Sunway, Selangor Darul Ehsan, Malaysia. ${ }^{3}$ Institute of Pharmaceutical Sciences (IPS), University of Veterinary \& Animal Sciences (UVAS), Lahore, Pakistan. ${ }^{4}$ Department of Pharmacy, COMSATS University Abbottabad campus Abbottabad, Abbottabad, Pakistan. ${ }^{5}$ Department of Biology, Faculty of Science, Selcuk University, Campus/Konya, Turkey. ${ }^{6}$ Department of Health Sciences, Faculty of Science, University of Mauritius, Réduit, Mauritius. ${ }^{7}$ Department of Pharmacy, University 'G. d'Annunzio" of Chieti-Pescara, 66100 Chieti, Italy. ${ }^{8}$ Liquid Chromatography Mass Spectrometery (LCMS) Platform, Monash University, Jalan Lagoon Selatan, 47500 Bandar Sunway, Selangor Darul Ehsan, Malaysia.

Received: 15 May 2020 Accepted: 22 September 2020

Published online: 16 October 2020

\section{References}

1. Krishnaiah D, Sarbatly R, Nithyanandam R. A review of the antioxidant potential of medicinal plant species. Food Bioprod Process. 2011:89(3):217-33.

2. Lovkova MY, Buzuk GN, Sokolova SM, Kliment'eva NI. Chemical features of medicinal plants. App Biochem Microbiol. 2001;37(3):229-37.

3. Uniyal SK, Singh KN, Jamwal P, Lal B. Traditional use of medicinal plants among the tribal communities of Chhota Bhangal, Western Himalaya. J Ethnobiol Ethnomed. 2006:2(1):14.

4. Ali JS, Khan I, Zia M. Antimicrobial, cytotoxic, phytochemical and biological properties of crude extract and solid phase fractions of Monotheca buxifolia. Oriental Pharmacy Exp Med. 2020;20(1):115-22.

5. Ruiz JM, Rivero RM, Lopez-Cantarero I, Romero L. Role of Ca $2+$ in the metabolism of phenolic compounds in tobacco leaves (Nicotiana tabacum L.). Plant Grow Regul. 2003;41(2):173-7.

6. Rashid AB, Marwat SK. Ethnobotanical study of important wild plants of Bahadur Khel tract (tehsil Banda Daud Shah) in Karak district. Gomal Univ J Res. 2006:2(2):165-72.

7. Khan JA, Ullah I, Adhikari A, Shahid M. Hepatoprotective effect of Monotheca buxifolia fruit against antitubercular drugs-induced hepatotoxicity in rats. Bangladesh J Pharmacol. 2016;11(1):248-56. 
8. Ullah I, Khan JA, Adhikari A, Khan A, Hannan PA, Wadood A, Farooq U. Bioassay-guided isolation of new urease inhibitory constituents from Monotheca buxifolia (Falc.) fruit and their molecular docking studies. Records Nat Prod. 2016;10(6):744.

9. Hazrat A, Nisar M, Zaman S. Antibacterial activities of sixteen species of medicinal plants reported from Dir Kohistan Valley KPK, Pakistan. Pak J Bot. 2013:45(4):1369-74.

10. Ullah I, Khan JA, Shahid M, Khan A, Adhikari A, Hannan PA, Javed I, Shakee F, Faroog U. Pharmacological screening of Monotheca buxifolia (Falc.) A. DC. for antinociceptive, anti-inflammatory and antipyretic activities. BMC Comp Alt Med. 2016;16(1):273.

11. Jan S, Khan MR, Rashid U, Bokhari J. Assessment of antioxidant potential, total phenolics and flavonoids of different solvent fractions of Monotheca buxifolia fruit. Osong Public Health Res Persp. 2013;4(5):246-54.

12. Rehman J, Khan IU, Farid S, Kamal S, Aslam N. Phytochemical screening and evaluation of in-vitro antioxidant potential of Monotheca buxifolia. E3 J Biotechnol. Pharm Res. 2013:4(4):54-60.

13. Ullah I, Khan JA, Iqbal Z, Hannan PA, Nasir F, Muhammad S, Jahan S, Rehman M. Chemical composition, anti-bacterial and cytotoxic potential of n-hexane soluble fraction of monotheca buxifolia (falc) a. dc. Fruit. Nat Acad Sci Lett. 2017:40(6):405-8.

14. Khan I, Ali JS, UI-Haq I, Zia M. Biological and phytochemicals properties of Monotheca buxifolia: an unexplored medicinal plant. Pharm Chem J. 2020; 54:293-301.

15. Saleem H, Zengin G, Locatelli M, Ahmad I, Khaliq S, Mahomoodally MF, Hussain R, Rengasamy KR, Mollica A, Abidin SA, Ahemad N. Pharmacological, phytochemical and in-vivo toxicological perspectives of a xero-halophyte medicinal plant: Zaleya pentandra (L.) Jeffrey. Food Chem Toxicol. 2019;131:110535.

16. Saleem H, Htar TT, Naidu R, Nawawi NS, Ahmad I, Ashraf M, Ahemad N. Biological, chemical and toxicological perspectives on aerial and roots of Filago germanica (L.) huds: functional approaches for novel phytopharmaceuticals. Food Chem Toxicol. 2019;123:363-73.

17. Marini G, Graikou K, Zengin G, Karikas GA, Gupta MP, Chinou I. Phytochemical analysis and biological evaluation of three selected Cordia species from Panama. Ind Crop Prod. 2018;120:84-9.

18. Yerlikaya S, Zengin G, Mollica A, Baloglu MC, Celik Altunoglu Y, Aktumsek A. A multidirectional perspective for novel functional products: in vitro pharmacological activities and in silico studies on Ononis natrix subsp hispanica. Front Pharmacol. 2017;8:600.

19. Murugan R, Parimelazhagan T. Comparative evaluation of different extraction methods for antioxidant and anti-inflammatory properties from Osbeckia parvifolia Arn.-an in vitro approach. J King Saud Uni Sci. 2014;26(4):267-75.

20. Do QD, Angkawijaya AE, Tran-Nguyen PL, Huynh LH, Soetaredjo FE, Ismadji S, Ju YH. Effect of extraction solvent on total phenol content, total flavonoid content, and antioxidant activity of Limnophila aromatica. J Food Drug Anal. 2014;22(3):296-302.

21. Ito Y. Golden rules and pitfalls in selecting optimum conditions for high-speed counter-current chromatography. J Chromatography A. 2005;1065(2):145-68.

22. Schmeda-Hirschmann G, Theoduloz C, Jiménez-Aspee F, Echeverría J. Bioactive constituents from south American Prosopis and their use and toxicity. Curr Pharma Design. 2020;26(5):542-55.

23. Vlaisavljević S, Jelača S, Zengin G, Mimica-Dukić N, Berežni S, Miljić M, Stevanović ZD. Alchemilla vulgaris agg.(Lady's mantle) from Central Balkan: antioxidant, anticancer and enzyme inhibition properties. RSC Adv. 2019. 9(64):37474-83.

24. Afrin S, Gasparrini M, Forbes-Hernandez TY, Reboredo-Rodriguez P, Mezzetti B, Varela-López A, Giampieri F, Battino M. Promising health benefits of the strawberry: a focus on clinical studies. J Agri Food Chem. 2016;64(22):4435-49.

25. Molina MF, Sanchez-Reus I, Iglesias I, Benedi J. Quercetin, a flavonoid antioxidant, prevents and protects against ethanol-induced oxidative stress in mouse liver. Biol Pharm Bull. 2003;26(10):1398-402.

26. Shen SQ, Zhang $Y$, Xiang JJ, Xiong CL. Protective effect of curcumin against liver warm ischemia/reperfusion injury in rat model is associated with regulation of heat shock protein and antioxidant enzymes. World J Gastroenterol. 2007;13(13):1953.

27. Wu Y, Benjamin EJ, MacMahon S. Prevention and control of cardiovascular disease in the rapidly changing economy of China. Circulation. 2016;133(24): 2545-60.

28. Prakash M, Basavaraj BV, Murthy KC. Biological functions of epicatechin: plant cell to human cell health. J Functional Foods. 2019;52:14-24.
29. Si H, Lai CQ, Liu D. Dietary Epicatechin, A Novel Anti-aging Bioactive Smal Molecule. Curr Med Chem. 2020. https://doi.org/10.2174/ 0929867327666191230104958.

30. Sattanathan K, Dhanapal CK, Umarani R, Manavalan R. Beneficial health effects of rutin supplementation in patients with diabetes mellitus. J App Pharm Sci. 2011;1(8):227.

31. Almajano MP, Carbo R, Jiménez JA, Gordon MH. Antioxidant and antimicrobial activities of tea infusions. Food Chem. 2008;108(1):55-63.

32. Abdel-Hameed ES. Total phenolic contents and free radical scavenging activity of certain Egyptian Ficus species leaf samples. Food Chem. 2009;114(4):1271-7.

33. Shon MY, Kim TH, Sung NJ. Antioxidants and free radical scavenging activity of Phellinus baumii (Phellinus of Hymenochaetaceae) extracts. Food Chem. 2003:82(4):593-7.

34. Mocan A, Schafberg M, Crișan G, Rohn S. Determination of lignans and phenolic components of Schisandra chinensis (Turcz.) Baill. Using HPLC-ESIToF-MS and HPLC-online TEAC: contribution of individual components to overall antioxidant activity and comparison with traditional antioxidant assays. J Functional Foods. 2016;24:579-94.

35. Uysal S, Senkardes I, Mollica A, Zengin G, Bulut G, Dogan A, Glamočlija J, Soković M, Lobine D, Mahomoodally FM. Biologically active compounds from two members of the Asteraceae family: Tragopogon dubius Scop. and Tussilago farfara L. J Biomol Struc Dynamics. 2019;37(12):3269-81.

36. Meneses-Gutiérrez CL, Hernández-Damián J, Pedraza-Chaverri J, GuerreroLegarreta I, Téllez DI, Jaramillo-Flores ME. Antioxidant capacity and cytotoxic effects of catechins and resveratrol oligomers produced by enzymatic oxidation against T24 human urinary bladder cancer cells. Antioxidants. 2019;8(7):214.

37. Flora SJ. Structural, chemical and biological aspects of antioxidants for strategies against metal and metalloid exposure. Oxidative Med Cell Longevity. 2009;2:Article ID 873634.

38. Ebrahimzadeh MA, Pourmorad F, Bekhradnia AR. Iron chelating activity, phenol and flavonoid content of some medicinal plants from Iran. African J Biotechnol. 2008;7(18)

39. Najjaa H, Zerria K, Fattouch S, Ammar E, Neffati M. Antioxidant and antimicrobial activities of Allium roseum L."Lazoul," a wild edible endemic species in North Africa. Inter J Food Proper. 2011;14(2):371-80.

40. Sousa EO, Miranda CM, Nobre CB, Boligon AA, Athayde ML, Costa JG. Phytochemical analysis and antioxidant activities of Lantana camara and Lantana montevidensis extracts. Ind Crop Prod. 2015;70:7-15.

41. Llorent-Martínez EJ, Ortega-Barrales P, Zengin G, Mocan A, Simirgiotis MJ, Ceylan R, Uysal S, Aktumsek A. Evaluation of antioxidant potential, enzyme inhibition activity and phenolic profile of Lathyrus cicera and Lathyrus digitatus: potential sources of bioactive compounds for the food industry. Food Chem Toxicol. 2017;107:609-19.

42. Quinn DM. Acetylcholinesterase: enzyme structure, reaction dynamics, and virtual transition states. Chem Rev. 1987;87(5):955-79.

43. Hoffman BB. Neurotransmission: the autonomic and somatic motor nervous systems. In: Goodman \& Gilman's the pharmacological basis of therapeutics; 1996. p. 105-40

44. Giacobini E. Cholinesterase inhibitors: from the Calabar bean to Alzheimer therapy. Cholinesterases and cholinesterase inhibitors. 2000:181-226.

45. Alcântara VM, Oliveira LC, Réa RR, Suplicy HL, Chautard-Freire-Maia EA Butyrylcholinesterase activity and metabolic syndrome in obese patients. Clin Chem Lab Med. 2005;43(3):285-8.

46. Furtado-Alle L, Andrade FA, Nunes K, Mikami LR, Souza RL, Chautard-Freire-Maia EA. Association of variants of the- 116 site of the butyrylcholinesterase BCHE gene to enzyme activity and body mass index. Chem Int. 2008;175(1-3):115-8.

47. Iwasaki T, Yoneda M, Nakajima A, Terauchi Y. Serum butyrylcholinesterase is strongly associated with adiposity, the serum lipid profile and insulin resistance. Inter Med. 2007:46(19):1633-9.

48. Silva IM, Leite N, Boberg D, Chaves TJ, Eisfeld GM, Eisfeld GM, Bono GF, Souza $R L$, Furtado-Alle L. Effects of physical exercise on butyrylcholinesterase in obese adolescents. Genet Mol Biol. 2012;35(4):741-3.

49. Wei J, Zhang XY, Deng S, Cao L, Xue QH, Gao JM. a-Glucosidase inhibitors and phytotoxins from Streptomyces xanthophaeus. Nat Prod Res. 2017; 31(17):2062-6

50. Thilagam E, Parimaladevi B, Kumarappan C, Mandal SC. a-Glucosidase and a-amylase inhibitory activity of Senna surattensis. J Acupunct Meridian Stud. 2013:6(1):24-30

51. Wickramaratne MN, Punchihewa JC, Wickramaratne DB. In-vitro alpha amylase inhibitory activity of the leaf extracts of Adenanthera pavonina. BMC Comp Alt Med. 2016;16(1):466 
52. Sun L, Guo Y, Zhang Y, Zhuang Y. Antioxidant and anti-tyrosinase activities of phenolic extracts from rape bee pollen and inhibitory melanogenesis by CAMP/MITF/TYR pathway in B16 mouse melanoma cells. Front Pharmacol. 2017:8:104.

53. Parvez S, Kang M, Chung HS, Bae H. Naturally occurring tyrosinase inhibitors: mechanism and applications in skin health, cosmetics and agriculture industries. Phytother Res. 2007;21(9):805-16.

54. Sarkar D, Agustinah W, Woods F, Coneva E, Vinson E, Shetty K. In vitro screening and evaluation of phenolic antioxidant-linked anti-hyperglycemic functions of rabbit-eye blueberry (Vaccinium ashei) cultivars. J Berry Res. 2017;7(3):163-77.

\section{Publisher's Note}

Springer Nature remains neutral with regard to jurisdictional claims in published maps and institutional affiliations.

Ready to submit your research? Choose BMC and benefit from:

- fast, convenient online submission

- thorough peer review by experienced researchers in your field

- rapid publication on acceptance

- support for research data, including large and complex data types

- gold Open Access which fosters wider collaboration and increased citations

- maximum visibility for your research: over $100 \mathrm{M}$ website views per year

At BMC, research is always in progress.

Learn more biomedcentral.com/submissions 